
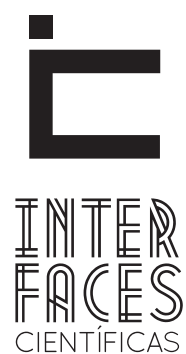

EDUCAÇÃO

ISSN IMPRESSO 2316-333X

ISSN ELETRÔNICO 2316-3828

\title{
HISTORIOGRAFIA DIDÁTICA E ENSINO DE HISTÓRIA: NAÇ̃̃O E IDENTIDADE NAS NARRATIVAS SOBRE A HISTÓRIA DO BRASIL [1843-1861]
}

Maria Aparecida de Leopoldino Tursi Toledo

\section{RESUMO}

0 principal objetivo deste escrito é refletir sobre as relações que historicamente vieram sendo tecidas entre História e ensino na perspectiva relacional de dois campos de conhecimentos: a Educação e a História, a fim de compreender melhor a novidade das questões que habitam em nosso presente quando se trata de pensar os aspectos pedagógicos dessa disciplina escolar no cenário da educação escolar brasileira contemporaneamente. 0 leitor encontrará nas reflexões aqui desenvolvidas a problematização da trajetória assumida pela história como disciplina escolar no caminho de sua afirmação como saber socialmente necessário no decorrer do século XIX. A escolha metodológica desse caminho se justifica por entender que, como parte dos interesses pedagógicos, é necessário, na discussão sobre História e ensino de História, pen- sar o ensino tradicional por meio de pelo menos dois aspectos que são centrais nessa questão: a tradição historiográfica (entendida como escrita da história) e sua relação com a historiografia didática (a escrita da história escolar) que inaugura um método específico de ensinar o passado no decorrer do século XIX, mais especificamente por intermédio de duas obras historiográficas de referência do período - Como se deve escrever a história do Brasil, de Martius (1843) e Lições de História do Brasil, de Joaquim Manoel de Macedo (1861).

\section{PALAVRAS-CHAVE}

Historiografia Didática. Ensino de História. Identidade. Nação. 


\section{ABSTRACT}

The main purpose of this writing is to reflect on the relationships that historically came being woven between history and education in the relational perspective of two fields of knowledge: Education and History, in order to better understand the novelty of the questions that dwell in our present when it comes thinking about the pedagogical aspects school discipline in the scenario of Brazilian contemporaneously education. The reader will find here the reflections developed problematize the trajectory assumed by history as a school subject in the way of his claim to know how socially necessary throughout the nineteenth century. The methodological choice of this path is justified by understanding that, as part of the pedagogical interests, is necessary in the discussion of his- tory and history teaching, think traditional education through at least two aspects that are central in this issue: a historiographical tradition (understood as the writing of history) and its relation to the didactic historiography (the writing of school history) that opens a specific method of teaching the past in the course of the nineteenth century, more specifically through two historical works reference period - How should write the history of Brazil, Martius (1843) - and History Lessons from Brazil, Joaquim Manoel de Macedo (1861).

\section{KEYWORDS}

Didatic Historiography. History Teaching. Identity. Nation.

\section{RESUMEN}

El objetivo principal de este escrito es reflexionar sobre las relaciones que históricamente se registra entre la historia y la educación en la perspectiva relacional de dos áreas de conocimiento: Historia y Educación con el fin de comprender mejor la novedad de las cuestiones que habitan en nuestro presente cuando se trata de pensar en los aspectos pedagógicos de la disciplina escolar en el escenario brasileño contemporáneamente educación. El lector encontrará aquí las reflexiones desarrolladas y que problematizan la trayectoria asumida por la historia como disciplina escolar en el camino de su pretensión de saber cómo socialmente necesario durante todo el siglo XIX. La elección de la metodología de este camino se justifica por la comprensión de que, como parte de los intereses pedagógicos, es necesario en la discusión de la historia y la en- señanza de la historia , pensar la educación tradicional a través de al menos dos aspectos que son centrales en este tema : una tradición historiográfica ( entendida como escritura de la historia) y su relación con la historiografía didáctica ( la escritura de la historia de la escuela ) que abre un método específico de enseñanza del pasado en el transcurso del siglo XIX, más concretamente, a través de dos obras históricas periodo de referencia - Como debería escribir la historia de Brasil, Martius (1843 ) - Lecciones de Historia de Brasil, Joaquim Manoel de Macedo ( 1861 ).

\section{PALABRAS CLAVE}

Historiografia. Enseñanza de la Historia. La identidad. La Nación 


\section{INTRODUÇ̃̃̃o}

0 principal objetivo deste escrito é refletir sobre as relações que historicamente vieram sendo tecidas entre História e ensino na perspectiva relacional de dois campos de conhecimentos: a Educação e a História, a fim de compreender melhor a novidade das questões que habitam em no presente, quando se trata de pensar os aspectos pedagógicos dessa disciplina escolar no cenário da educação escolar brasileira contemporaneamente.

Tal escolha se fez, porque se entende que superar o ensino tradicional dessa disciplina hoje requer o diálogo com o campo educacional, no sentido de entender os nexos existentes entre história, ensino de História e historiografia, na busca por elucidar as questões que envolvem a permanência da produção de um saber histórico considerado tradicional na prática pedagógica do professor na atualidade.

Por esse caminho, tratar do tema Ensino de História demanda inicialmente reconhecer que, se a palavra história pode designar um modo especifico de investigação, pode, também, fazer referência à vivência humana percebida de diferentes maneiras pelos atores sociais. E o termo ensino de História não é apenas um fluxo da produção acadêmica que é transposto didaticamente para situações escolares. 0 ensino de História se vincula diretamente a história vivida, sendo parte mais ampla da relação entre história da forma como é praticada dentro da academia e além dela.

O ensino de História deve ser percebido como uma disciplina escolar que se relaciona, mas não se confunde, com a história acadêmica. Dessa maneira, o leitor irá encontrar nas reflexões aqui desenvolvidas a problematização da trajetória assumida pela história como disciplina escolar no caminho de sua afirmação como saber socialmente necessário no decorrer do século XIX.
Ao refletir sobre o que vem a ser um ensino tradicional de História, se fará por meio do próprio trajeto histórico da disciplina, por entender que, como parte dos interesses pedagógicos, é necessário, na discussão sobre História e ensino de História, pensar o ensino tradicional por meio de pelo menos dois aspectos que são centrais nessa questão: a tradição historiográfica (entendida como escrita da história) e sua relação com a historiografia didática (a escrita da história escolar) que inaugura um método específico de ensinar o passado no decorrer do século XIX.

Para tanto, inicia-se problematizando o ensino tradicional e suas relações com uma Pedagogia da Nação que se firma na conjuntura das contendas sobre a constituição da Escola Pública na França, palco dos debates que se travaram em torno das finalidades sociais dessa disciplina e marcou a configuração de um modelo de ensino do passado do qual o Brasil é herdeiro.

A respeito desse diálogo com o cenário francês, busca-se mostrar, sem correr o risco de simplesmente adequar à situação brasileira aquele modelo - uma vez que cada país resolveu suas controvérsias com pauta especifica -, como a elite brasileira se apropriou dele para o desempenho de funções que lhes eram complementares, quais sejam: pensar a formação da identidade nacional.

Em suma, entende-se que pensar Didática no ensino de História é percorrer as relações entre dois campos de conhecimentos que se relacionam mutuamente - a Educação e a História - no sentido de reconhecer na prática pedagógica desafios contemporâneos que tem marcado a disciplina na escola contemporânea. Por esse motivo escolheu-se iniciar esta conversa discutindo as continuidades e permanências didático-pedagógicas que se fazem presentes no quadro das tendências historiográficas contemporâneas. 


\section{UMA PEDAGOGIA DA NAÇÃO: ASPECTOS DA IDENTIDADE DO ENSINO DE HISTÓRIA}

François Furet (1927-1997), historiador contemporâneo estudioso do período moderno, ao discutir o "nascimento da história" em um capítulo específico na conhecida obra A Oficina da História (s/d), indicou pontos importantes para se compreender esse trajeto e os nexos que historicamente se estabeleceram entre história e ensino, eixo norteador das questões pedagógicas que envolvem o debate sobre didática e ensino de História no tempo presente.

Furet (s/d) observa que o nascimento dessa disciplina escolar pode ser observado claramente em meados do século XIX, no cenário francês, quando a nação passa a ser uma questão fundamental para os países europeus. De acordo com o autor, nesse momento foi possível verificar que a história passa a ter um método e objeto próprio, capazes de caracterizá-la como uma disciplina autônoma e pedagogicamente definida, já que em momentos anteriores, como apontou Bruter (1997), a história estava entre as letras clássicas, não se constituindo como um saber disciplinar propriamente dito.

Essa mudança de seu estatuto é marcada, conforme indicou Bruter, por uma mudança epistêmica e semiótica, cuja síntese se fez organicamente inseparável de uma necessidade de "precisão científica”, em dois âmbitos que se relacionam mutuamente até hoje: o da produção do conhecimento em história realizado nas instituições de pesquisa e o da produção de saberes históricos, efetuada nas instituições de ensino escolar.

O trajeto de afirmação da história como saber escolar, no entanto, obedeceu as lutas políticas diretamente travadas em torno da formação do Estado-nacional no cenário francês para a consolidação da Escola Pública, Laica, Universal e Gratuita.
Furet (s/d), ao indicar como o ensino de História tornou-se tema de debates na França revolucionária e disciplina escolar socialmente necessária, afirma:

A III República Francesa nascente assume por fim toda a herança nacional em nome do povo, porque ela própria é, finalmente, e quase ao fim de um século, a Revolução Francesa no poder: essa figura provisória, mas que vai revelar-se bastante duradoura, é constituída por um poder conservador que governa em nome dos valores revolucionários. A partir deste momento a história já não constitui apenas uma matéria de ensino secundário ou superior, é também indispensável aos mais pequenos, cujo juízo e patriotismo devem ser formados cedo. (FURET, s/d, p. 127-128).

O historiador alerta para o fato de que, a partir daquele momento, o ensino de História esteve sob o signo da Nação. A preocupação com a inclusão da História Pátria nos programas curriculares franceses designava a renovação do ensino como interesse de um projeto nacional que, sob a autoridade republicana, indicava o caminho para o progresso, conforme assinala Hery (1999, p. 45): “[...] os republicanos desejavam fundar uma nova moral e uma nova unidade nacional, e livrar a sociedade das superstições e preconceitos na qual conservavam os religiosos". Louis René de Caradeuc de La Chalotais (1701-1785 apud PETITAT, 1994, p. 141), jurista francês que em 1763 publicou a obra Educação Nacional criticando o ensino jesuítico, traduz bem esse desejo, nestas palavras:

\footnotetext{
O ensino das leis divinas é assunto da Igreja, mas o ensino da moral é atributo do Estado [...]. Como se pode ter pensado que homens que não são vinculados ao Estado, que estão acostumados a colocar um religioso acima do chefe do Estado [...] seriam capazes de educar e instruir a juventude de um reino? [...] Assim, o ensino de todas as nações, esta porção da legislação que é a base e o fundamento dos Estados, permanece sob a direção imediata de um regime cujo centro se encontra para além dos Alpes, necessariamente inimigo das nossas leis. Que inconsequência e que escândalo.
} 
Tal afirmação apontava para a separação do Estado e da Igreja no que se refere à escola republicana e, ao mesmo tempo, para a necessidade de uma educação moral laica. A Lei de Jules Ferry (1832-1893), ministro da Instrução Pública na França na década de 80, expressava esse intento:

A lei de 28 de março de 1882 se caracteriza por duas disposições que se completam sem contradizer-se: de um lado, deixa fora do programa obrigatório o ensino de qualquer dogma religioso; de outro, põe no primeiro plano o ensino moral e cívico. A instrução religiosa pertence às famílias e à Igreja, a instrução moral à escola. (FERRY, 1945, p. 14. Grifo nosso).

Segundo Hery, já com as leis constitucionais de 1875, reforçava-se o sentimento nacional de que era preciso enraizar-se na República para fortificá-la. Diz a autora: "Assim, o tema da unidade se desloca do campo estritamente nacional para o âmbito político e social e estrutura-se na mensagem que a instrução escolar veicula" (HERY, 1999, p. 71. Grifo nosso).

A laicização do ensino (1882) e a separação da Igreja do Estado (1905), que aconteceram nesse movimento, impulsionaram mudanças nos conteúdos das disciplinas escolares. Quanto a isso, o historiador francês Ernest Lavisse (1842-1922), do alto de seu posto como professor da Sorbonne, diretor da Escola Normal Superior e diretor da rubrica de história da $R e-$ vue de Paris, se perguntava:

Qual saber escolar pode mesmo dar aos alunos o sentimento de continuidade da obra humana a não ser ensinando as matérias clássicas e suas mutações que exige adaptação a um mundo transformado e o alargamento dos horizontes que incite "deixar às margens do Mediterrâneo?" Como melhor conjugar a universalidade da condição humana e a identidade das nações? (LAVISSE, 1842-1922 apud HERY, 1999, p. 47).

Para Hery, Lavisse está sendo muito claro, pois a noção de identidade das nações, o "nós" significa notadamente "nós, franceses", e a disciplina capaz de possibilitar esse saber, a História. Para a autora Lavisse (1842-1922 apud HERY, 1999, p. ?) "de uma manei- ra viva a vontade de dar a prioridade às realidades nacionais", na medida em que coloca sob os ombros do passado o peso político de conciliar presente e futuro.

Pierre Nora confirma esse trajeto francês ao afirmar que os historiadores da França, a exemplo de Lavisse e Jules Michelet (1798-1874),

[...] estavam imbuídos do sentimento de que seu papel consistia em estabelecer uma memória mais positiva do que as precedentes, mais globalizantes e mais explicativas. 0 arsenal científico do qual a história foi dotada no século passado [XIX] só serviu para reforçar poderosamente o estabelecimento crítico de uma memória verdadeira. Todos os grandes remanejamentos históricos consistiram em alargar o campo da memória coletiva. (NORA, 1993, p. 10).

Verificando as relações entre sentimento nacional e o seu uso como educação cívica, Hery informa que na escola, tanto pública como privada, os jovens franceses aprendiam, por meio dos livros didáticos, a história da França desde os tempos antigos, de forma a contribuir para enraizar a ideia (a memória) de perenidade da França. Esse sentimento era referência, assim como nos compêndios de História, também nos livros de leitura para a infância à época.

Segundo André Petitat, o estudo de Mainguene$\mathrm{au}^{2}$ sobre os livros de leitura em uso sob a III República torna mais nítido os contornos morais e os valores leigos republicanos. Diz Petitat (1994, p. 158):

\begin{abstract}
Todos eles valorizam o trabalho e o estudo, atacam a preguiça, honram a bravura do soldado, pedem respeito ao Estado; mas há uma profunda diferença de perspectiva entre os das congregações e os dos republicanos. Os primeiros citam constantemente as principais virtudes, a ordem social e as maravilhas da natureza, relacionando-as à Providência. Em “Joãozinho”, protótipo do livro escolar clerical, a evocação dos grandes homens não passa dos personagens biblícos, das grandes figuras cristãs, dos monarquistas e dos combatentes pela França. Já no "Viagem pela França", cartilha laica por excelência, as alusões a Deus são evitadas;
\end{abstract}

2. MAINGUENEAU, D. Os livros de Escola da República (1870-1914). Paris: Sycomore, 1979. 
Bossuet e Fenelon são excluídos em 1905; não aparece nenhum rei; a tônica é dada para os sábios, os homens de letras, os administradores e os combatentes ilustres. Nenhum dos dois tem a pretensão de seguir passo a passo a história da França; os grandes personagens são a encarnação desta ou daquela virtude; trata-se, simplesmente, de uma coleção histórica de valores exemplares.

É dessa maneira que o ensino de História da França une moral e civismo para concretizar o ideal de uma memória nacional soberana e una. "A França é o mais belo país, sua língua é a mais clara, seus soldados são os mais bravos: ela se reserva um lugar de primeiro plano entre as nações" (PETITAT, 1994, p. 158).

Estudar a história da França, diz Hery (1999), consistia na narração de uma experiência contínua e coletiva em nome da unidade do país, guardando os meios de sua afirmação no futuro, como são exemplares as palavras de Gabriel Monod (apud HERY, 1999, p. 68): "todos se sentirão os rebentos do mesmo sol, os filhos da mesma raça, de forma alguma renegando parte da herança paternal, todos descendentes da velha França e ao mesmo tempo, cidadãos da França moderna".

Dessa forma, a história, quando contempla no decorrer do século XIX um método cientifico, contempla, também, um dispositivo pedagógico, não se definindo, por isso, apenas por um conhecimento cientifico, mas estruturalmente como um saber didático-pedagógico que deveria articular ciência e pedagogia para informar sobre o passado da nação.

É necessário, portanto, acrescentar essa discussão da relação da História ensinada com a memória coletiva para além da perspectiva cognitiva, para se compreender o que tem marcado o ensino tradicional de História nos marcos da historiografia contemporânea e avançar a abordagem da questão feita por mediação do debate sobre as ideais pedagógicas.
O manual e o compêndio escolar tornam-se, nesse contexto, importante instrumento para compreender as características assumidas pelo ensino tradicional de História no quadro das tendências historiográficas. Exatamente porque o tradicional se faz não apenas pela prática pedagógica dos professores, mas, sobretudo, pelos conteúdos cristalizados e a abordagem historiográfica não problematizadora. Perspectiva pedagógica que ultrapassa o ambiente escolar e adquire grande repercussão social e política, mostrando a importância do papel da escola - e do ensino de História - em um debate que, na verdade, estavam em jogo as posições do presente e o projeto de futuro de cada sociedade.

Percorrer esse trajeto implica retomar os estudos sobre o nascimento da História como disciplina escolar e sua institucionalização como saber que ensina a memória da nação no contexto brasileiro, explorando essa relação a partir dos nexos existentes entre educação e sociedade. Nesse percurso importará recortar a questão para mostrar que o cerne do problema de atribuições e finalidades educativas da memória como História efetua-se, como se verá, no próprio movimento de institucionalização do Estado Nacional brasileiro que, ao inaugurar a nação, inaugura, também, uma História escolar e seu método de ensinar.

Um elemento a ser considerado, quando se faz referencia ao ensino tradicional em História, é, portanto, considerar que a questão da memória envolve uma tradição historiográfica presente na escrita da história escolar que não se compreende os aspectos didático-pedagógicos caso não se debruce sobre suas dimensões históricas. Por isso, ao se efetuar a reflexão sobre a relação que se estabelece entre ensino de História e memória, se fará a partir de um recorte de marcada importância para o debate sobre a História ensinada na educação básica, que é a afirmação desta disciplina no século XIX no interior das discussões sobre a escola pública no Brasil. 
É consenso e generalizadamente conhecido que a historiografia do Império teve na constituição do Instituto Histórico e Geográfico Brasileiro (IHGB) em 1838 o principal, embora não o único centro divulgados de textos históricos, atuando no processo de fortalecimento do Estado Monárquico. Fundado com a pretensão de tornar-se arquivo e guardião da história brasileira, estabeleceu diretrizes sobre o que se deveria ou não ser historicizado. No mesmo sentido - de ser um "lugar de memória" - foi criado o Imperial Colégio de Pedro II como modelo e padrão do ensino secundário, em 1837 no Rio de Janeiro. Nele a história se firma como disciplina escolar em 1838.

Entretanto, logo de início um problema impunha-se para ambas as instituições: com a Independência havia-se criado o Estado, mas o que seria a Nação diante de um processo separatório da metrópole tão singular como o foi o brasileiro?

Nesse cenário, momento inicial de construção simbólica e discursiva de uma nacionalidade brasileira, o conceito de identidade nacional se vinculou à necessidade premente das elites, que levaram a cabo o processo de independência, de formular uma interpretação do país que mantivesse sua extensa unidade territorial, fortalecendo a centralização político-administrativa do reinado de D. Pedro I (1822-1831). No entanto, até aquele momento essa história era inexistente e a ideia de um país unificado estava em formação ${ }^{3}$. Por isso se diz que:

A invenção política de uma independência trabalhada a partir do príncipe herdeiro português representou um desafio a mais na tarefa de pensar a Nação: passou a significar pensar a sua história. Novas palavras

3. O projeto de criar um passado para a Pátria brasileira envolveu a participação de importantes instituições acadêmicas (Instituto Histórico e Geográfico Brasileiro e o Colégio Pedro II) que, por intermédio de seus intelectuais, viam na educação fator decisivo para a inserção do Brasil no contexto das "nações civilizadas". Ver, entre outros: NADAI, Elza. O ensino de história no Brasil: trajetórias e perspectivas. Revista Brasileira de História, v.13, n.25/26, set.1992/ago.1993; BITTENCOURT, Identidade nacional e ensino de História no Brasil. In. KARNAL, L. (org.) História na sala de aula: conceitos, práticas e propostas. São Paulo: Cortez, 2003 e conceitos, que deram colorido ao século XIX, foram convocados e ou reconstruídos: Pátria e Nação, liberdade e patriotismo foram os primeiros. 0 período inicial do país independente foi então marcado pela busca de sua história - suas raízes nacionais. Estas precisavam ser encontradas no passado colonial. (GASPARELLO, 2011, p.33-34, grifos no original).

Estava, portanto, colocado o problema: como escrever a história de uma nação que até então tinha sido colônia? Uma história que não poderia ser qualquer uma, mas uma história "que não deslustrasse suas elites ante ao mundo civilizado". 0 desafio estava posto e não era insignificante: conhecer o passado colonial para nele buscar os elementos que pudessem corresponder a uma identidade brasileira nos marcos de um processo civilizador ${ }^{4}$.

De acordo com o estudo de Arlette Medeiros Gasparello (2011), um importante manual é escrito nesse momento, o Resumo de História do Brasil até 1828, de autoria de um militar português chamado Henrique Luiz de Niemeyer Bellegarde ${ }^{5}$, editado em 1831. De inspiração francesa ${ }^{6}$, tal manuscrito constitui um primeiro modelo de livro didático de História do Brasil com a clara finalidade de "dar a conhecer o Brasil" aos “jovens compatriotas”.

No Resumo, Bellegarde apresenta a história do Brasil em épocas, de forma que o país aparece assim divido: O Brasil antes da conquista; O Brasil conquistado pelos portugueses; O Brasil sob o domínio espanhol; O Brasil livre do jugo de Espanha7; O Brasil

\footnotetext{
4. O conceito de Processo Civilizador está referenciado na obra de Norbert Elias (1993).

5. Nascido em Lisboa (1802), veio para o Brasil na viagem que trouxe a família real portuguesa (seu pai, também militar, comandou um destacamento de artilharia da nau Príncipe Regente). Morreu com 37 anos. (Gasparello, 2011).

6. Gasparello afirma que o resumo de Bellegarde seria uma tradução do Resumé de L'histoire du Brésil do autor francês Ferdinand Denis que o publicara seis anos antes da versão brasileira e que teria chamado a atenção dos membros do IHGB.

7. De acordo com Gasparello (2004, p.102), o domínio espanhol "torna-se marco referencial de duas épocas e palco de acontecimentos importantes para a nação, como o despertar do patriotismo. No Brasil livre do jugo espanhol nasce a ideia de liberdade, mas num movimento marcado pela incúria de seus conjurados mineiros".
} 
como sede da monarquia portuguesa; O Brasil Império Constitucional e Independente. Na avaliação de Gasparello,

O Resumo apresenta uma narrativa em linguagem simples, sem muitos detalhes de eventos e datas, mas contém as marcas de um nacionalismo romântico do período inicial da nossa independência, em que o sentimento e a ação patriótica inspiravam-se na ideia de Nação construída em oposição ao colonizador português. (GASPARELLO, 2011, p.45. Grifo nosso).

A referência à ideia de um nacionalismo romântico relaciona-se a compreensão que Bellegarde deixava transparecer de que no Brasil havia "um povo pequeno e sem recursos, mas cheio do mais nobre patriotismo", que o teria levado ao processo de formação de um Estado-nação. Processo que é narrado em "tom de exaltação" à forma pela qual "um povo ardente e nobre" realizou a sua autonomia política em 1822 (GASPARELLO, 2004, p. 102). Considerado um instrumento para atender à Pedagogia da Nação ${ }^{8}$, o Resumo, que foi aprovado por Circular da Câmara Municipal em 1834 como compêndio escolar, apresentou o conteúdo do passado que serviu para materializar a imagem de Nação que no momento a elite política brasileira buscava.

Escrito sob o impacto da mudança política e das expectativas que emergem com as novas experiências de um país livre, o compêndio de Bellegarde que serviu para o ensino primário e secundário nas escolas da Corte - é representativo de uma tradição historiográfica escolar marcada pelos debates políticos dos primeiros tempos do Brasil independente. Ele foi útil para apresentar uma possibilidade de narrar a história do Brasil relacionando Pátria com Nação e deixou suas marcas no ensino de História que se seguiu. É dessa maneira que o "mito fundador" do país

8. Conceito utilizado por François Furet $(\mathrm{s} / \mathrm{d})$ relacionadamente ao de Pedagogia do Cidadão.

9. Termo utilizado por Marilena Chauí (2001, p. 7) para designar a forte presença de uma representação homogênea que persiste na memória social dos brasileiros. Representação que "permite, em certos momentos, crer na unidade, na identidade e na indivisibilidade da nação e do e da nacionalidade brasileira vem acompanhada de um projeto de ensino de História que tinha por finalidade explicar qual era o caráter nacional e patriótico do "povo brasileiro".

A nação que emerge de sua narrativa fundamenta uma história patriótica - presentificada na memória social que ajudou a construir nos dois últimos séculos -, embora sem, ainda, o peso de uma história imperial, oficial e pedagógica que marcou o segundo momento, a década de 1860 com Joaquim Manoel de Macedo. Tal década marcará a criação de um modelo legitimado pelo Império de uma História da Nação sob a perspectiva de escritores nacionais e, como se verá mais à frente, um método de ensino para a História.

Apesar de a narrativa continuar a ser de exaltação da Pátria, os tempos eram de preocupações com a definição da "nação brasileira", o que se esperava era que os nacionais se pusessem a escrever sua história. Pensar o que era a nação naquela década era se defrontar com as questões de diferenças étnicas e culturais enraizadas no passado colonial. A problemática política central girava em torno de saber: como ser uma nação sem definir claramente o que era o "povo" dessa nação? A elite intelectual deveria enfrentar as questões pendentes sobre o papel do "indígena", do "negro", do "colono português" ao tratar da "nacionalidade brasileira", exatamente num momento em que as relações estabelecidas entre esses grupos, no tempo colonial, se apresentavam como um "problema candente” para explicar a unidade do país.

Essa temática tornou-se o desafio enfrentado pelo Instituto Histórico Geográfico Brasileiro (IHGB) que, em 1845, premiou a monografia do naturalista alemão Karl Friedrich Philip von Martius, após concurso em que os candidatos deveriam redigir sobre "Como escrever a história do Brasil", e, nove anos depois, quando apoiou a publicação da

povo brasileiro, e, em outros momentos, conceber a divisão social e a divisão política sob a forma dos amigos da nação e dos inimigos a combater". 
obra, de origem nacional, do membro institucional Francisco Adolfo de Varnhagen, História Geral do Brasil (1854).

Na dissertação de Martius, a escrita da história do Brasil deveria priorizar os seguintes itens: Os índios (a raça cor de cobre); os portugueses (de cor branca ou caucasiana); a raça africana (de cor preta ou etiópica) em suas relações para com a história do Brasil, de forma que o historiador do Brasil:

[...] jamais deverá perder de vista quais os elementos que aí concorrerão para o desenvolvimento do homem. São porém estes elementos de natureza muito diversa, tendo para a formação do homem convergido de um modo particular três raças, a saber: a de côr de cobre ou americana, a branca ou caucasiana, e enfim a preta ou etiópica. Do encontro, da mescla, das relações mútuas e mudanças dessas três raças, formou-se a atual população, cuja história por isso mesmo tem um cunho muito particular. (MARTIUS, 1953, p. 187).

Investigar minuciosamente a vida e as histórias do “desenvolvimento aborígenes americanos"; estendendo as suas investigações além do tempo da conquista, "prescrutinará a história dos habitantes primitivos do Brasil”. História que "por ora não dividida em épocas distintas, nem oferecendo monumentos visíveis, ainda está envolta em obscuridade, mas que por esta mesma razão excita sumamente a nossa curiosidade" (MARTIUS, 1953, p. 190). Isso porque:

Só depois de haver estabelecido um juízo certo sôbre a natureza primitiva dos autóctonos brasileiros, poder-se-á continuar a mostrar, como se formou o seu estado moral e físico por suas relações com os emigrantes; em que êstes influiram por leis e comércio, e comunicação, sôbre os índios, e qual a parte que toca os boçais filhos da terra no desenvolvimento das relações sociais dos portuguêses emigrados. (MARTIUS, 1953, p. 190).

Depois de traçar um quadro das contribuições dos nativos seria a vez de tratar do "elemento português". $\mathrm{Na}$ análise de Martius ele se mostra no centro do descobrimento e desenvolvimento da História do Brasil.
Quando os portuguêses descobriram o Brasil, e nêle se estabeleceram, acharam os indígenas proporcionalmente em tão diminuto número e profundo aviltamento, que nas suas recem-fundadas colônias podiam desenvolver e estender-se quase sem importar-se dos autôctonos. Êstes exerceram sôbre os colonos uma influência negativa tão somente por quanto só os forçaram a acautelar-se contra as invasões hostis, e por isso criaram uma instituição singular de defesa, o Sistema das milícias. [...] vemos que a posição guerreira, em que se colocou o colono português para com o índio, contribuiu muito para a rápida descoberta do interior do país, como igualmente para a extensão do domínio português. (MARTIUS, 1953, p. 194).

$\mathrm{Na}$ análise do naturalista transparece a ideia de que toda a ação do português contribuiu para o processo de "descobrimento e colonização primitiva do Brasil”. Fato histórico que não pode ser compreendido, segundo o autor, senão em seu nexo com as façanhas marítimas, comerciais e guerreiras dos portugueses, "[...] que de modo algum pode ser considerado fato isolado na história dêsse povo ativo, e que sua importância e relações com o resto da Europa está na mesma linha com as emprêsas dos portuguêses" (MARTIUS, 1953, p. 194). De forma que na apreciação de Martius a escrita da História do Brasil deveria estar em constante relação com a História Universal:

O historiógrafo do Brasil ver-se-á arrastado por tais observações a jamais perder de vista na história da colonização do Brasil, e do seu desenvolvimento civil e legislativo (que acompanhava aquela ao mesmo passo), os movimentos do comércio universal de então, e incorporá-los mais ou menos extensamente à sua história [...]. Assim, por exemplo, está a história do descobrimento do Brasil intimamente ligada com a história comercial de madeira índia chamada japan, que vulgarmente conhecida debaixo do nome de pau brasil, legno brasilo, bresil, etc., foi a causa principal de dar-se à Terra de Santa Cruz o nome de Terra do Brasil. Também a história e o movimento mercantil dos metais e pedras preciosas têm as mais estreitas relações com a história do Brasil, e finalmente a das plantas tropicais úteis, conhecidas na Europa depois da descoberta do Novo Mundo, jámais poderá ser separada da história da colonização do Brasil. (MARTIUS, 1953, p. 195-196). 
Por fim trata das contribuições da "raça africana". Para o autor, seria importante para o historiador indagar a condição dos negros importados, seus costumes, suas opiniões civis, seus conhecimentos naturais, preconceitos e superstições, os "defeitos e virtudes próprias à sua raça em geral”, se quiser demonstrar como "tudo reagiu sobre o Brasil".

Sendo a África visitada pelos protuguêses antes da descoberta do Brasil, e tirando êles dêste país grandes vantagens comerciais, é fora de dúvida que já naquele período influia nos costumes o desenvolvimento de Portugal. Por êste motivo devemos analisar as circunstâncias das colônias portuguêsas na África, de tôdas as quais se trafica em escravatura para o Brasil, dever-se-á mostrar que movimento imprimiam na indústria, agricultura e o comércio das colônias africanas para com as do Brasil, e vice-versa. (MARTIUS, 1953, p. 201).

O historiador do Brasil deveria investigar todos os fatores sociais, econômicos, climáticos, políticos, geográficos, culturais, da composição do povo brasileiro e, por consequência, de sua nacionalidade. Numa palavra:

Nunca por tanto o historiador da Terra de Santa Cruz há de perder de vista que a sua tarefa abrange os mais grandiosos elementos; que não the compete tão somente descrever o desenvolvimento de um só povo, circunscrito em estreitos limites, mas sim de uma nação cuja crise e mescla atuais pertencem à história universal, que ainda se acha no meio de seu desenvolvimento superior. Possa ele não reconhecer em tão singular conjunção de diferentes elementos algum acontecimento desfavorável, mas sim a conjuntura mais feliz e mais importante no sentido da mais pura filantropia. (MARTIUS, 1953, p. 201. Grifo nosso).

Assim, o compromisso do historiador com sua pátria, segundo Martiuns, era o desenvolvimento de uma História da Nação vista como integrante do universo europeu, que pudesse difundir sentimentos e pensamentos do mais nobre patriotismo entre os nacionais. Uma obra histórica, segundo a opinião do autor, deveria ter igualmente "a tendência de despertar e reanimar em seus leitores brasilei- ros amor da pátria, coragem, constância, indústria, fidelidade, prudência, todas as virtudes cívicas" (MARTIUS, 1953, p. 201). Fazer o povo sentir-se como membros de um país único, como um todo unido. Para isso, mostrar as belezas naturais de que - Brasil se compõe e a harmonia das três raças que o sustentava era fundamental.

Varnhagen, por sua vez, foi mais enfático quando tratou do papel ocupado pelas "raças" no desenvolvimento do Brasil. Em sua obra História Geral do Brasil anunciou:

Bem meditadas todas as questões acerca dos índios, quer em relação a eles unicamente, quer com respeito aos colonos, quer à partilha de glória que thes deve caber na história de cada uma das nações americanas, podem elas reduzir-se nos seguintes pontos:

1. Eram os que percorriam o nosso território, à chegada dos cristãos europeus, os seus legítimos donos?

2. Viviam, independentemente da falta do ferro e de conhecimento da verdadeira religião, em um estado social invejável?

3. Esse estado melhoria, sem o influxo externo que mandou a Providencia por meio do cristianismo?

4. Havia meios de os reduzir e amansar, sem empregar a coação pela força?

5. Houve grandes excessos de abuso nos meios empregados para essas reduções?

6. Dos três principais elementos de povoação, índio, branco e negro, que concorreram ao desenvolvimento de quase todos os países da América, qual predomina hoje no nosso?

7. Quando se apresentem discordes ou em travada luta estes três elementos no passado, qual deles devemos supor representante histórico da nacionalidade hoje? (VARNHAGEN, 1854, p. IX. Grifo nosso).

Buscava-se, como se vê, reconhecer o papel de cada grupo social - então entendido como raças - na construção da nacionalidade. 0 conceito de nação ligava-se, portanto, a uma concepção de "povo" que precisava ser mais bem definida. Era o momento de determinar, também, os principais fatos que marcavam a história da nação, seus agentes e papéis nessa 
construção. Mas para Varnhagen a questão já estava definida, sem meias palavras afirma:

Quereis saber o que é a nação brasileira? Olhai para o próprio brasão d'armas que a simboliza. Nele vereis a esfera armilar, significando a origem da dinastia e a do Estado, e nele vereis também a cruz da ordem de Cristo, que representa por si só a história da civilização do país. E isto não escrito neste ou naquele idioma, ininteligível aos demais povos; mas apregoado na bela linguagem heráldica, composta de hieroglíficos, que constituem, nos feitos históricos, uma espécie de pasigrafia ao alcance de todas as nações civilizadas. (VARNHAGEN, 1854, p. XXV. Grifo nosso).

Com esses argumentos conclui-se que o europeu era o que mais representava a nacionalidade brasileira e a Nação estava historicizada nos símbolos nacionais "civilizadores" do Estado que se firmou com a independência em 1822.

A concepção do IHGB sobre a natureza do conhecimento histórico foi determinante na configuração da pesquisa e do ensino (por meio do Colégio Pedro II) no Brasil. Por esses motivos é que a historiografia do império foi, durante muito tempo, matriz do estudo das instituições políticas e do discurso fundador da nacionalidade. Dentro dessa característica, só se podia endossar a consolidação da hegemonia política das elites que projetaram a nação (DIAS, 1998).

Por isso, situar a produção do IHGB relativamente ao que foi seu programa de intervenção cultural e político interessa tanto à crítica das representações que se instituíram como memória e, também, para a desmontagem dessa memória da nação brasileira que ficou na escrita da história escolar nesse país.

Nesse sentido, portanto, se entende que a crítica ao ensino tradicional de História requer, na atualidade, que se dirija, também, a esse aspecto do problema, percebida neste capítulo como continuidade e permanência, uma longa duração, no ensino de His- tória no Brasil. Ou seja, fazer a crítica ao ensino tradicional de História ainda hoje implica em reconhecer a tradição historiográfica que consolida a história como disciplina escolar no Brasil e seus aspectos didático-pedagógicos.

\section{ESCRITA DA HISTÓRIA, NARRATIVA E MÉTODO: O ENSINO DE HISTÓRIA NO BRASIL NO SÉCULO XIX}

Até da década de 1860, os compêndios destinados ao ensino de História, mesmo tendo sido aprovados pelo Conselho Superior de Instrução Pública para o ensino na Corte e adotado no Imperial Colégio Pedro II, sofreram restrições. Como apontou Gasparello (2004), tais restrições advinham do fato de que esses compêndios e manuais, como foi o caso do Resumo de Bellegarde (1831), basearam-se em autores estrangeiros e, de acordo com os estudos da autora, embora estivessem sido amplamente utilizados nas aulas de História no Pedro II, eles "não conquistaram um lugar na memória do Colégio" pelo fato de não terem sido escritos por um nacional e possivelmente em função de não terem produzido um método de ensinar necessário ao período.

O compêndio de Joaquim Manoel de Macedo (1820-1882), por sua vez, foi amplamente aceito e divulgado pelas autoridades imperiais. Sua obra Lições de História do Brasil para uso dos alunos do Imperial Colégio de Pedro // teve grande repercussão no ensino de História a partir da década de 1860, marcando um período importante na história desse ensino no país.

Conforme observou Gasparello (2004, p. 130, grifo nosso), o compêndio de Macedo, ao contrário dos outros que o antecedeu, "encontrou todas as condições favoráveis ao sucesso: veio preencher uma lacuna de um compêndio especialmente escrito para os alunos do Colégio e foi escrito de acordo com o seu plano de estudos". Além do que, seu autor era "membro efetivo da instituição legitimadora da escrita da 
História didática e erudita” e, também, professor do Colégio mais importante e prestigioso da época. Sua “inovação" estava justamente na declaração de ter a intenção de elaborar um compêndio que imprimisse um método de ensino para a História, resultado, como ele mesmo observa, de sua experiência docente.

Nascido no interior fluminense, Macedo, como era comum entre os letrados da época, tinha formação em Medicina pela Faculdade do Rio de Janeiro e tornou-se famoso no campo não só da história, mas nas letras em geral. Reconhecido como um importante romancista brasileiro foi, também, poeta e dramaturgo. Além disso, participou de comissões destinadas a redigir pareceres a respeito de compêndios que os autores levavam ao IHGB para aprovação, apoio na publicação e conferir o privilegio de adoção por estabelecimentos oficiais (MATTOS, 1993; GASPARELLO, 2004).

A organização do compêndio de Macedo é exemplar de um momento em que se buscava uma forma de estruturar o texto em uma narrativa historiográfica que, ao mesmo tempo, apresentasse o conteúdo e o método de ensinar. Com Macedo, como apontam seus estudiosos, "ficam reunidos, no compêndio, as práticas dos principais agentes desse processo: ao que ensina, oferece o texto, que lê ou faz ler; ao aluno, oferece um caminho para aprender, com a síntese em quadros explicativos" (GASPARELLO, 2004, p. 132).

0 método de ensinar história presente na obra já estava antevisto no próprio título. Ou seja, ensinar por “lições”. A compilação de textos de autores reconhecidos, numa re-elaboração discursiva na perspectiva da linguagem e objetivos, foi a marca dessa obra didática que, por sua vez, cristalizou uma forma escolar de compreender o livro didático de História no Brasil: a organização do texto em lições, a exposição da matéria e a síntese de cada lição num quadro sinótico.

O compêndio, composto desses quatro elementos didáticos, materializa o método de ensino do autor que correspondia ao movimento didático-pedagógico a ser percorrido por professor e alunos do decorrer da aula. Método de ensino que ainda hoje se percebe clara ou veladamente - como continuidade de uma prática didático-pedagógica inaugurada nesse período.

É dessa forma que se pode afirmar que a Pedagogia Histórica implícita no compêndio de Macedo, por meio de uma proposta de conteúdos a serem ensinados e de um método de ensinar, são as duas faces da Pedagogia da Nação que corresponde ao seu tempo e lugar de afirmação. No caso, “[...] a proposta curricular de um projeto nacional, com o passado reconstruído para servir na formação de pessoas identificadas com uma nação imaginada num país chamado Brasil" (GASPARELLO, 2004, p. 131).

A proposta didática de Macedo se firma na conjuntura de uma historiografia voltada para a história política da nação, como se viu anteriormente. Nesse sentido é que se deve compreender a unidade de um ensino tradicional em História, ou seja, o papel que reserva a disciplina no universo escolar bem como seus conteúdos criteriosamente selecionados. No prefácio do compêndio Macedo informa que nas lições seria enfatizada a "apreciação dos fatos importantes". Pensados na perspectiva da Pedagogia da Nação, os fatos mais importantes eram aqueles vinculados a memória do passado nacional.

Nesse sentido, a presença de datas, fatos, feitos, personagens é marcante na obra de Macedo porque participam desse ideário em que está em jogo o projeto de futuro da sociedade, de forma que o "tradicional” não responde apenas a um modelo pedagógico ou a um conjunto de ideias pedagógicas abstrato, mas às questões socioculturais de uma época e lugar.

Obra de grande repercussão nas escolas brasileiras, inclusive no Paraná (TOLEDO, 2005), as Lições de Macedo foi, em larga medida, divulgadoras da historiografia de Varnhagen. 
De perfil conservador ela ajudou a cristalizar, com suas sucessivas reedições, o método de ensino que cumpria o papel de legitimar e, ao mesmo tempo, de pôr em destaque o lugar do Império brasileiro no conserto das nações civilizadas, permitindo, dessa maneira, a construção de uma identidade e de uma memória nacionais. De forma que as Lições seriam a expressão de unidade entre um conteúdo e um método de ensinar o passado que ainda hoje é reconhecido como característico de um ensino tradicional.

Diante dessa estratégia de ensino, que foi muito comum no século XIX, a prática do magistério vivida por Macedo à época percebia como dificuldades a serem enfrentadas na aprendizagem e como tentativa de "[...] resolver as principais dificuldades encontradas pelos alunos para memorizar as lições, principal atividade solicitada aos alunos na pedagogia da época e que se prolongou nas escolas durante muito tempo, até o século XX”. De modo que "decorar, recitar, falar de memória os textos, poesias, verbos, números, nomes de reis, ministros, generais, eram a base do ensino nas escolas: palmatórias, cafua (prisão do aluno na escola), era a contrapartida para os relapsos" (GASPARELLO, 2004, p. 132, grifos nossos).

O quadro sinótico era o dispositivo didático com o qual se pretendia auxiliar nessa difícil tarefa de dispor da memória cognitiva para aprender sobre os fatos, os atributos, os personagens memoráveis da história pátria. Ele compunha-se das seguintes colunas: Personagens; Atributos; Feitos e Acontecimentos e Datas. Ao lado do texto das lições, nas margens, aparecem em destaque as datas referentes aos assuntos tratados. De forma que ressaltar os personagens, seus atributos, datas e fatos era o eixo norteador do método de ensinar.

Mergulhada em seu tempo, a prática educativa centrada na memorização de conteúdos correspondia a um conjunto de procedimentos didáticos que ultrapassa a percepção da questão pelo viés de um isola- mento correspondente a escolha do professor, como dá a entender as criticas contemporâneas a esse método de ensinar História atualmente.

Não se trata apenas de uma postura do professor diante do saber do aluno e seu papel como educador, mas sim de um conjunto de procedimentos didático-pedagógicos que, num determinado momento histórico, concorreu para o resultado de um ensino com tais características. Reconhecer esse conjunto de motivadores é fundamental para compreender a problemática do método tradicional de ensino em sua historicidade. Isso porque, por meio do quadro sinótico, fixou temas, edificou valores, defendeu crenças, situou o "lugar" de cada grupo social na história nacional, ergueu-se um panteão de heróis e marcaram-se datas que se transformaram nos marcos da história nacional que ainda hoje se apresenta como principal característica de um ensino tradicional de História.

\section{REFERÊNCIAS}

\section{BRUTER, Annie. L'Histoire Enseignée au Grand Siè- cle. Berlin, 1997.}

BURKE, Peter. História como memória social. In.: Variedades de História Cultural. Rio de Janeiro: Civilização Brasileira, 2000.

FURET, François. A Oficina da História. Tradução: Adriano Duarte Rodrigues. Lisboa: Gradiva, s/d.

GASPARELLO, Arlette Medeiros. Construtores de identidades: a pedagogia da nação na escola secundaria brasileira. São Paulo: Iglu, 2004.

GASPARELLO, Arlette Medeiros. Um desafio para a educação: ensinar Brasil aos brasileiros. In.:TOLEDO, Maria A.Leopoldino T. (Org). Ensino de História: ensaios sobre questões teóricas e práticas. Maringá: Eduem, 2011. 
HERY, Evelyne. Lês enjeux de l'enseignement de l'histoire (1880-1902). In.: Um siècle de leçons d'histoire, 18701970. Presses Universitaires de Rennes, 1999.

LE GOFF, Jacques. História e Memória. Tradução: Bernardo Leitão. 4.ed. Campinas: UNICAMP, 1996.

MACEDO, Joaquim Manoel de. Lições de Historia do Brazil para uso dos alumnos do Imperial Collegio de Pedro Segundo. Rio de Janeiro: Typ Imparcial, 1861.

MARTIUS. Carlos Frederico Ph. de. Como se deve escrever a História do Brasil. Dissertação de 1843. Revista do Instituto Histórico e Geográfico Brasileiro, v.219, 1953, p. 187.

MATTOS, Selma Rinaldi. Brasil em lições: a história do ensino de História no Brasil através dos manuais de Joaquim Manuel de Macedo. São Paulo, 1993.

SAVIANI, Dermeval. História das ideais pedagógicas no Brasil. Campinas: Autores Associados, 2007.

TOLEDO, Maria Aparecida Leopoldino T. A história ensinada sob o império da memória: questões de História da Disciplina. História, v.23, n.1-2, São Paulo, 2004, p. 13-22.

TOLEDO, Maria Aparecida Leopoldino T. A disciplina de História no Paraná: os compêndios de história e a história ensinada (1876-1905). Tese de Doutorado. Programa de Pós Graduação em Educação, Programa: História, Política, Sociedade. Pontifícia Universidade Católica de São Paulo, 2005.

VARNHAGEN, Francisco Adolpho de. História geral do Brasil. Madrid: Imprensa da V. Domingues, 1854. 